\title{
IMPLEMENTASI SISTEM INFORMASI MANAJEMEN DATA PERKARA PADA PENGADILAN TATA USAHA NEGARA BANJARMASIN
}

\author{
Auliya Rahman ${ }^{1)}$, Dwi Retno Sari ${ }^{2)}$ \\ ${ }^{1)}$ Fakultas Teknologi Informasi, Universitas Islam Kalimantan Muhammad Arsyad Al Banjari \\ ${ }^{2)}$ Fakultas Teknologi Informasi, Universitas Islam Kalimantan Muhammad Arsyad Al Banjari \\ ${ }^{1)}$ Email :auliyarahmankom@gmail.com \\ ${ }^{2}$ Email :dwiretnosarisari@yahoo.com
}

\begin{abstract}
Abstrak
Pengadilan Tata Usaha Negara Banjarmasin merupakan suatu lembaga peradilan dibawah Mahkamah Agung yang melaksanakan tugas kehakiman bagi rakyat pencari keadilan terhadap sengketa tata usaha negara. Di Pengadilan Tata Usaha Negara sendiri khusus nya pada bagian perkara, mempunyai tugas untuk mengelola data perkara yang dalam pengerjaannya di bantu dengan buku register perkara dan untuk membuat laporan dengan cara menggunakan semi komputer sehingga memerlukan waktu yang lama dalam pengerjaan serta kesulitan dalam pencarian data dan memungkinkan adanya kesalahan. Permasalahan yang akan dibahas pada penelitian ini adalah bagaimana penerapan sistem informasi manajemen data perkara pada Pengadilan Tata Usaha Negara Banjarmasin, agar bisa menyajian informasi yang cepat dan akurat dan data atau informasi yang dihasilkan dapat terkomputerisasi dan terintegrasi dengan baik yang meliputi penyajian data perkara baik itu tingkat pertama, banding, kasasi, pk, dan eksekusi serta data putusan perkara dan jadwal sidang. Metode membangun sistem informasi manajemen data perkara ini menggunakan metode waterfall. Adapun pemrograman yang digunakan menggunakan adalah PHP dan MySQL sebagai basis datanya. Dengan sistem informasi ini diharapkan dapat mempermudah dalam mengelola data perkara sehingga menghasilkan data dan informasi yang akurat, cepat, efektif dan efesien.
\end{abstract}

Kata Kunci : Sistem Infomasi, Manajemen Data Perkara, $P H P, M y S Q L$

\section{PENDAHUluan}

Peranan sistem informasi akan memberikan dampak terhadap kemajuan perusahaan dan instansi sudah tidak diragukan lagi. Dengan dukungan sistem yang baik maka sebuah perusahaan dan instansi akan memiliki berbagai keunggulan kompetentif. Pemanfaatan komputer sebagai alat kerja bantu, khususnya sebagai media pengolahan data, baik yang berskala besar maupun skala kecil terus berkembang dengan pesat. Itu semua berkat perkembangan teknologi yang didorong oleh keinginan manusia untuk dapat melakukan pekerjaan dengan cepat, tepat, dan aman.

Pengadilan Tata Usaha Negara (PTUN) Banjarmasin merupakan suatu lembaga peradilan dibawah Mahkamah Agung yang melaksanakan kekuasaan kehakiman bagi rakyat pencari keadilan terhadap sengketa Tata Usaha Negara. Sengketa Tata Usaha Negara adalah sengketa yang timbul dalam bidang Tata Usaha Negara antara orang atau badan hukum perdata dengan Badan atau Pejabat Tata Usaha Negara, baik pusat maupun di daerah. Di Pengadilan Tata Usaha Negara Banjarmasin khususnya dibagian perkara, mempunyai tugas untuk mengolah data administrasi perkara, seperti : data berkas perkara, data agenda, jadwal sidang, data hasil sidang, hasil SK putusan, arsip surat serta laporan-laporan lainnya. Semua data itu harus di kelola dengan baik dan benar.

Pengelolaan dokumen yang dihasilkan dari proses administrasi akan menyebabkan terjadinya penumpukan data, seperti meningkatnya kebutuhan akan ruang penyimpanan dokumen, peralatan, serta kesulitan dalam penemuan kembali dokumen apabila dibutuhkan. Sementara ini dalam pengelolaan data yang diterapkan dalam ruangan perkara dibantu dengan buku register perkara dan untuk membuat laporan dengan cara di ketik melalui Microsoft Word sehingga memakan waktu yang lama dalam pengerjaan. 
Data maupun laporan atau informasi data perkara masih kurang akurat, sistem semimanual yang digunakan saat ini masih kurang efisien dalam pengelolaan dokumen yang ada pada bagian data perkara, penyimpanan data dengan cara di simpan pada Microsoft Word membuat kesulitan dalam pencarian data dan memakan waktu yang cukup lama.

Pada zaman sekarang semuanya sudah serba cepat dan mudah, website merupakan sarana yang paling tepat digunakan untuk berbagi suatu informasi, dengan adanya internet maka semakin mudah dan cepatlah seorang untuk melakukan penyajian data, permasalahan waktu dan kesulitan jangkauan tempat yang jauh akan teratasi dengan mudah, dan tentunya akan mengurangi biaya operasional yang biasanya digunakan untuk menyajikan informasi.

Oleh karena itu, berdasarkan dari permasalahan yang ada, perlu sebuah sistem informasi yang mampu mempermudah proses penyimpanan maupun pengaksesan data dan informasi yang cepat dan akurat pada Pengadilan Tata Usaha Negara Banjarmasin seperti data perkara tingkat pertama, banding, kasasi, peninjauan kembali, eksekusi, perkara yang sudah putus dan jadwal sidang dengan sistem berbasis website agar dapat memberikan efesiensi dan efektifitas kerja yang lebih baik lagi, laporan atau informasi perkara dapat dihasilkan secara cepat, tepat dan akurat, serta dapat meintegrasikan dan terkomputerisasi baik dalam pengelolaan data perkara dan informasi sehingga lebih cepat, efektif dan akurat.

\section{METODE PENELITAN}

Metode dalam penelitian ini menggunakan metode waterfall. Berikut ada beberapa langkah dalam pembuatan sistem infromasi manajemen data perkara agar bisa berjalan sebagaimana mestinya dengan metode waterfall, yaitu:

\section{a. Requirement Analisis}

Tahapan ini pengembangan sistem diperlukan komunikasi yang bertujuan untuk memahami perangkat lunak yang diharapkan oleh pengguna dan batasan perangkat lunak tersebut. Informasi ini diperoleh melalui wawancara, diskusi dan survei langsung ke Instansi Pengadilan Tata Usaha Negara Banjarmasin. Informasi dianalisis untuk mendapatkan data yang dibutuhkan oleh pengguna.

\section{b. Sistem Design}

Spesifikasi kebutuhan dari tahap sebelumnya akan dipelajari dalam fase ini dan desain sistem disiapkan. Desain Sistem membantu dalam menentukan perangkat keras dan perangkat lunak serta sistem persyaratan dan juga membantu dalam mendefinisikan arsitektur dalam sistem informasi manajemen data perkara secara keseluruhan. Perancangan Sistem meliputi :

1) Rancangan database

a. Tabel Perkara TK1

Tabel 1. Tabel Perkara TK1

\begin{tabular}{||c||c||c||c|}
\hline \multicolumn{1}{|c||}{ Field } & Type & $\begin{array}{c}\text { Widt } \\
\text { h }\end{array}$ & Ket \\
\hline \hline id_tk1 & Varchar & 30 & $\begin{array}{c}\text { Primar } \\
\text { y Key }\end{array}$ \\
\hline \hline no_perkara_tk1 & Varchar & 30 & - \\
\hline jenis_perkara & Varchar & 20 & - \\
\hline \hline $\begin{array}{c}\text { tanggal } \\
\text { nama_penggug } \\
\text { at }\end{array}$ & Date & - & - \\
\hline \hline nama_tergugat & Varchar & 50 & - \\
\hline \hline $\begin{array}{c}\text { panitera_pengg } \\
\text { anti }\end{array}$ & Varchar & 100 & - \\
\hline \hline nama_hakim1 & Varchar & 50 & - \\
\hline \hline nama_hakim2 & Varchar & 50 & - \\
\hline \hline nama_hakim3 & Varchar & 50 & - \\
\hline \hline
\end{tabular}

b. Tabel Perkara Banding

Tabel 2. Tabel Perkara Banding

\begin{tabular}{|c|c|c|c|}
\hline Field & Type & $\begin{array}{c}\text { Widt } \\
\text { h }\end{array}$ & Ket \\
\hline id_banding & Varchar & 30 & $\begin{array}{l}\text { Primar } \\
\text { y Key }\end{array}$ \\
\hline $\begin{array}{c}\text { no_perkara_bandi } \\
\text { ng }\end{array}$ & Varchar & 30 & - \\
\hline id_tk1 & Varchar & 30 & $\begin{array}{l}\text { Foreig } \\
\text { n Key }\end{array}$ \\
\hline no_perkara_tk1 & Varchar & 30 & - \\
\hline jenis_perkara & Varchar & 20 & - \\
\hline tanggal & Date & - & - \\
\hline "nama_penggugat & Varchar & 50 & $\begin{array}{l} \\
\end{array}$ \\
\hline nama_tergugat & Varchar & 100 & ב- \\
\hline $\begin{array}{c}\text { panitera_penggan } \\
\text { ti }\end{array}$ & Varchar & 50 & - \\
\hline nama_hakim1 & Varchar & 50 & - \\
\hline
\end{tabular}




\begin{tabular}{|r||r||l||l||}
\hline nama_hakim2 & Varchar & 50 & - \\
\hline \hline nama_hakim3 & Varchar & 50 & - \\
\hline
\end{tabular}

c. Tabel Perkara Kasasi

Tabel 3.Tabel Perkara Kasasi

\begin{tabular}{|c|c|c|c|}
\hline Field & Type & $\begin{array}{c}\text { Widt } \\
\mathrm{h}\end{array}$ & Ket \\
\hline id_kasasi & $\begin{array}{c}\text { Varcha } \\
\mathrm{r}\end{array}$ & 30 & $\begin{array}{l}\text { Primar } \\
\text { y Key }\end{array}$ \\
\hline no_perkara_kasasi & $\begin{array}{c}\text { Varcha } \\
\text { r }\end{array}$ & 30 & - \\
\hline id_tk1 & $\begin{array}{c}\text { Varcha } \\
\mathrm{r}\end{array}$ & 30 & $\begin{array}{c}\text { Foreign } \\
\text { Key }\end{array}$ \\
\hline no_perkara_tk1 & $\begin{array}{c}\text { Varcha } \\
\mathrm{r} \\
\end{array}$ & 30 & - \\
\hline jenis_perkara & $\begin{array}{c}\text { Varcha } \\
\text { r }\end{array}$ & 20 & - \\
\hline tanggal & Date & - & - \\
\hline nama_penggugat & $\begin{array}{c}\text { Varcha } \\
\mathrm{r} \\
\end{array}$ & 50 & - \\
\hline nama_tergugat & $\begin{array}{c}\text { Varcha } \\
\mathrm{r} \\
\end{array}$ & 100 & - \\
\hline $\begin{array}{c}\text { panitera_penggant } \\
\mathrm{i} \\
\end{array}$ & $\begin{array}{c}\text { Varcha } \\
\mathrm{r} \\
\end{array}$ & 50 & - \\
\hline nama_hakim1 & $\begin{array}{c}\text { Varcha } \\
\mathrm{r} \\
\end{array}$ & 50 & - \\
\hline nama_hakim2 & $\begin{array}{c}\text { Varcha } \\
\mathrm{r} \\
\end{array}$ & 50 & - \\
\hline nama_hakim3 & $\begin{array}{c}\text { Varcha } \\
\text { r }\end{array}$ & 50 & - \\
\hline
\end{tabular}

d. Tabel Perkara Peninjauan Kembali

Tabel 4. Tabel Perkara PK

\begin{tabular}{|c|c|c|c|}
\hline Field & Type & $\begin{array}{r}\text { Wi } \\
\text { dth }\end{array}$ & Ket \\
\hline id_pk & Varchar & 30 & $\begin{array}{c}\text { Primary } \\
\text { Key }\end{array}$ \\
\hline no_perkara_pk & Varchar & 30 & - \\
\hline id_tk1 & Varchar & 30 & $\begin{array}{c}\text { Foreign } \\
\text { Key }\end{array}$ \\
\hline no_perkara_tk1 & Varchar & 30 & - \\
\hline jenis_perkara & Varchar & 20 & - \\
\hline tanggal & Date & - & - \\
\hline nama_penggugat & Varchar & 50 & - \\
\hline nama_tergugat & Varchar & 100 & - \\
\hline $\begin{array}{c}\text { panitera_penggan } \\
\text { ti }\end{array}$ & Varchar & 50 & - \\
\hline nama_hakim1 & Varchar & 50 & - \\
\hline nama_hakim2 & Varchar & 50 & - \\
\hline nama_hakim3 & Varchar & 50 & - \\
\hline
\end{tabular}

e. Tabel Perkara Eksekusi

Tabel 5. Tabel Perkara Eksekusi 1

\begin{tabular}{|c|c|c|c|}
\hline Field & Type & $\begin{array}{c}\text { Widt } \\
\text { h }\end{array}$ & Ket \\
\hline id_eksekusi & Varchar & 30 & $\begin{array}{l}\text { Primar } \\
\text { y Key }\end{array}$ \\
\hline $\begin{array}{c}\text { no_perkara_ekse } \\
\text { kusi }\end{array}$ & Varchar & 30 & - \\
\hline id_tk1 & Varchar & 30 & $\begin{array}{l}\text { Foreig } \\
\mathrm{n} \text { Key }\end{array}$ \\
\hline no_perkara_tk1 & Varchar & 30 & - \\
\hline jenis_perkara & Varchar & 20 & - \\
\hline Tanggal & Date & - & - \\
\hline "nama_penggugat & Varchar & 50 & 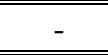 \\
\hline nama_tergugat & Varchar & 100 & - \\
\hline $\begin{array}{c}\text { panitera_penggan } \\
\text { ti }\end{array}$ & Varchar & 50 & - \\
\hline nama_hakim1 & Varchar & 50 & - \\
\hline " nama_hakim2 & Varchar & 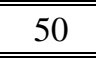 & - \\
\hline nama_hakim3 & Varchar & 50 & - \\
\hline
\end{tabular}

\section{2) Rancangan relasi tabel}

Berikut rancangan relasi tabel Sistem Informasi Manajemen Data Perkara Pada Pengadilan Tata Usaha Negara Banjarmasin.

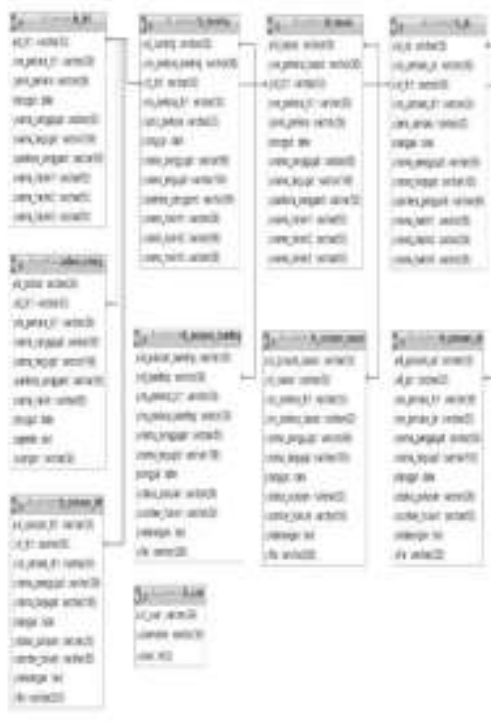

Gambar 1. Relasi Tabel

\section{c. Implementation}

Pada tahapi ini, sistem informasi manajemen data perkara pertama kali dikembangkan di program kecil yang disebut unit, yang terintegrasi dalam tahap selanjutnya. Setiap unit dikembangkan dan diuji untuk fungsionalitas yang disebut sebagai unit 
testing. Aplikasi yang di gunakan PHP dan MySQL untuk database.

\section{d. Integration \& Testing}

Seluruh unit yang dikembangkan dalam tahap implementasi diintegrasikan ke dalam sistem informasi manajemen data perkara pengujian yang dilakukan masing-masing unit. Setelah integrasi seluruh sistem diuji untuk mengecek setiap kegagalan maupun kesalahan.

\section{e. Operation \& Maintenance}

Tahap akhir dalam model waterfall. Dilakukan pemeliharaan termasuk dalam memperbaiki kesalahan yang tidak ditemukan pada langkah sebelumnya. Perbaikan implementasi unit sistem dan peningkatan jasa sistem sebagai kebutuhan baru supaya aplikasi ini bisa berjalan sebagaimana mestinya.

\section{HASIL DAN PEMBAHASAN}

Tampilan aplikasi merupakan hasil dari rancangan antarmuka yang telah dibuat sebelumnya. Berikut tampilan dan laporan sistem.

\section{a. Halaman Utama}

Pada halaman utama menampilkan menu aplikasi yang memuat kata-kata selamat datang di aplikasi, sekilas visi, serta motto Pengadilan Tata Usaha Negara Banjarmasin.

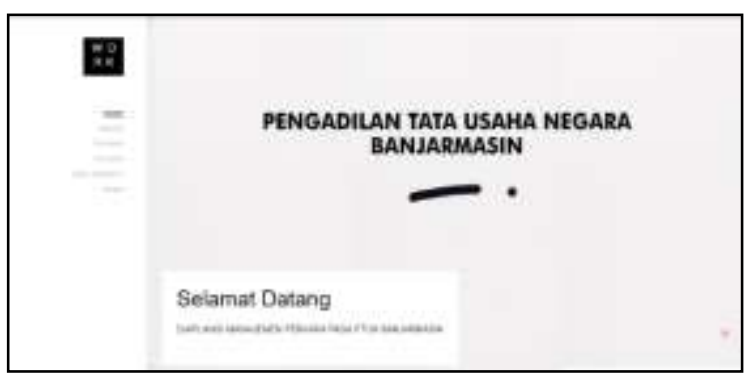

Gambar 2. Tampilan Antarmuka

\section{b. Login}

Pada halaman login berfngsi untuk keamanan aplikasi, seseorang yang tidak mempunyai hak akses teidak bisa mengakses program ini. Karena ketika ingin masuk kedalam sistem harus menggunakan username dan password yang benar.

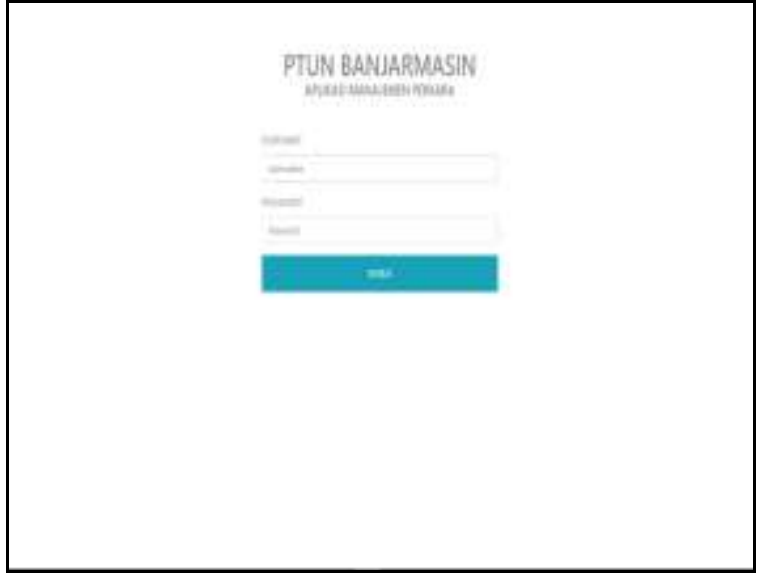

Gambar 3. Tampilan Antarmuka Login

\section{c. Menu Utama}

Setelah berhasil login pada menu utama ini pengguna akan dapat menggunakan fiturnya masing-masing sesuai hak akses.

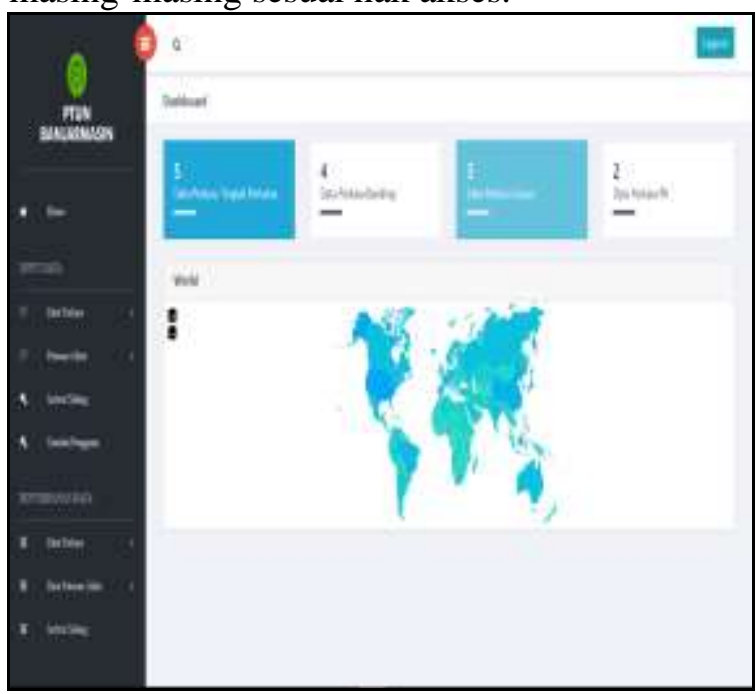

Gambar 4. Tampilan Antarmuka Menu Utama

\section{d. Input Perkara TK1}

Pada halaman input Perkara TK1 hanya admin yang mempunyai hak akses. Halaman ini berfungsi untuk menyimpan Perkara TK1 yang sudah terdaftar. 


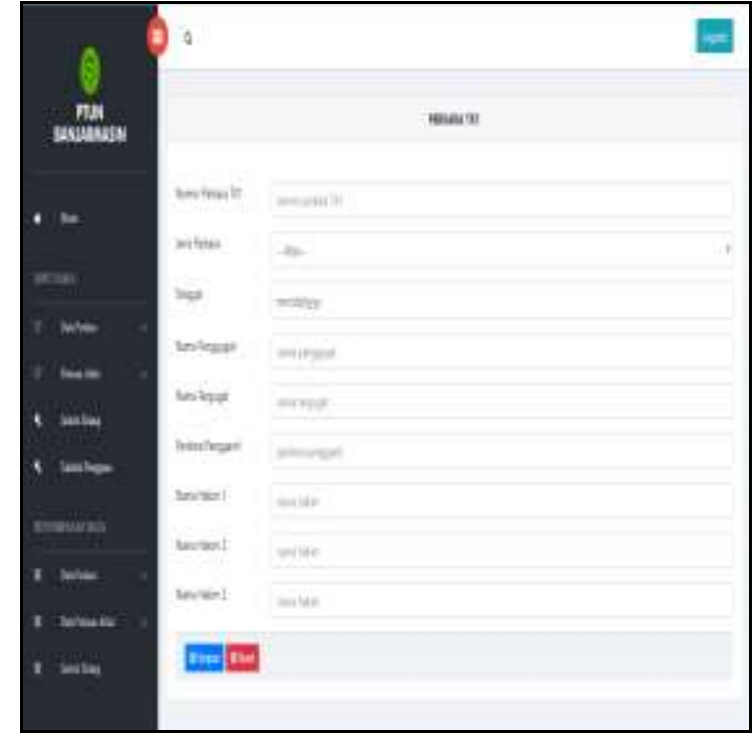

Gambar 5. Tampilan Input Perkara TK1

\section{e. Input Perkara Banding}

Pada halaman input Perkara Banding hanya admin yang mempunyai hak akses. Halaman ini berfusngi untuk menyimpan Perkara Banding yang sudah terdaftar.

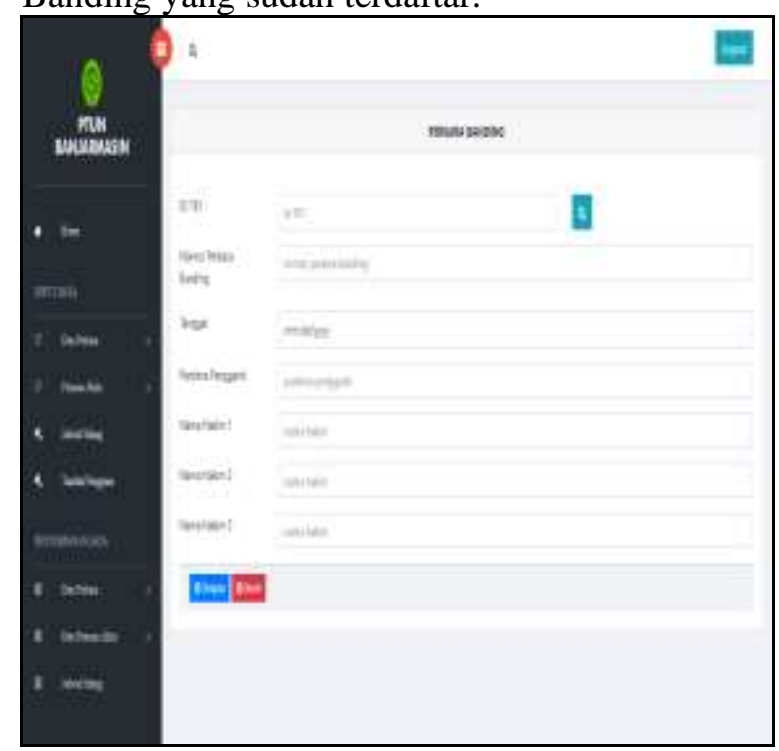

Gambar 6. Tampilan Input Perkara Banding

\section{f. Input Perkara Kasasi}

Pada halaman input Perkara Kasasi hanya admin yang mempunyai hak akses. Halaman ini berfungsi untuk menyimpan Perkara Banding yang sudah terdaftar.

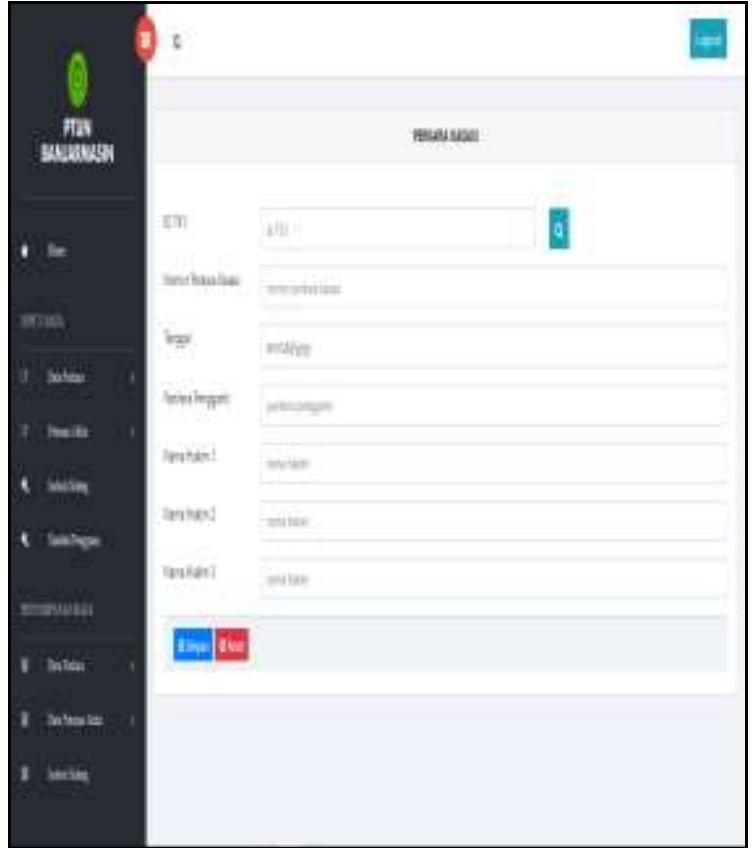

Gambar 7. Tampilan Input Perkara Kasasi

\section{g. Input Perkara PK}

Pada halaman input Perkara PK hanya admin yang mempunyai hak akses. Halaman ini berfungsi untuk menyimpan Perkara PK yang sudah terdaftar.

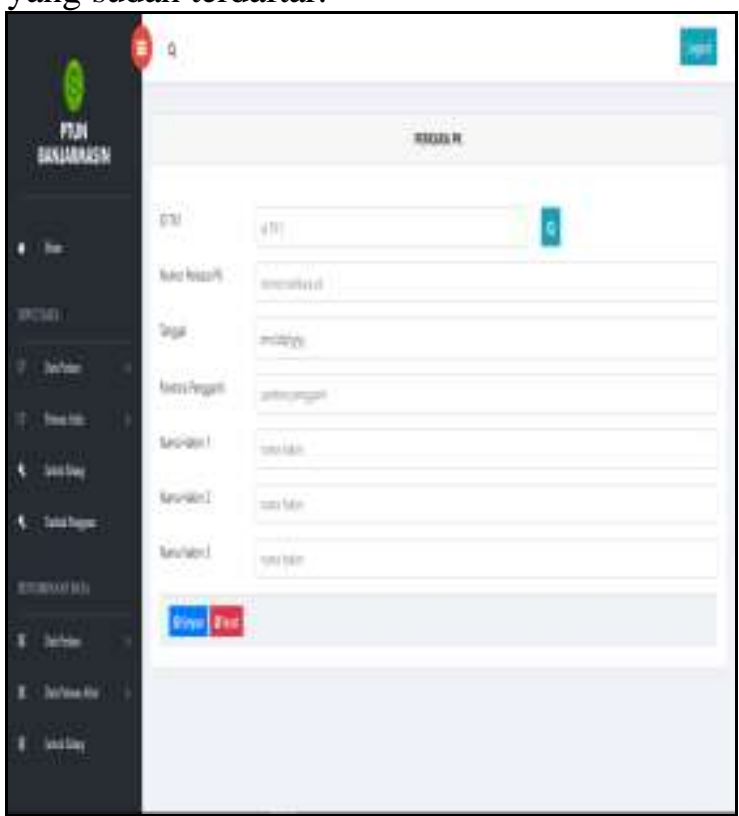

Gambar 8. Tampilan Input Perkara PK

\section{h. Input Perkara Eksekusi}

Pada halaman input Perkara Eksekusi hanya admin yang mempunyai hak akses. Halaman ini berfungsi untuk menyimpan Perkara Eksekusi yang sudah terdaftar. 


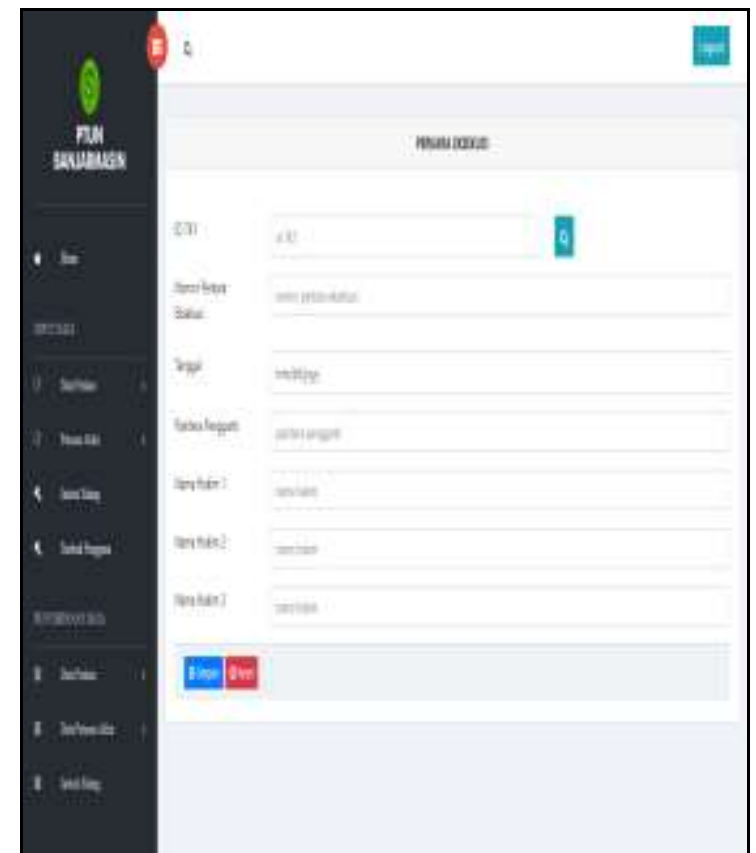

Gambar 9. Tampilan Input Perkara Eksekusi

\section{i. Input Jadwal Sidang}

Pada halaman input jadwal sidang hanya admin yang mempunyai hak akses. Halaman ini berfungsi untuk menginputkan setiap perkara yang akan sidang.

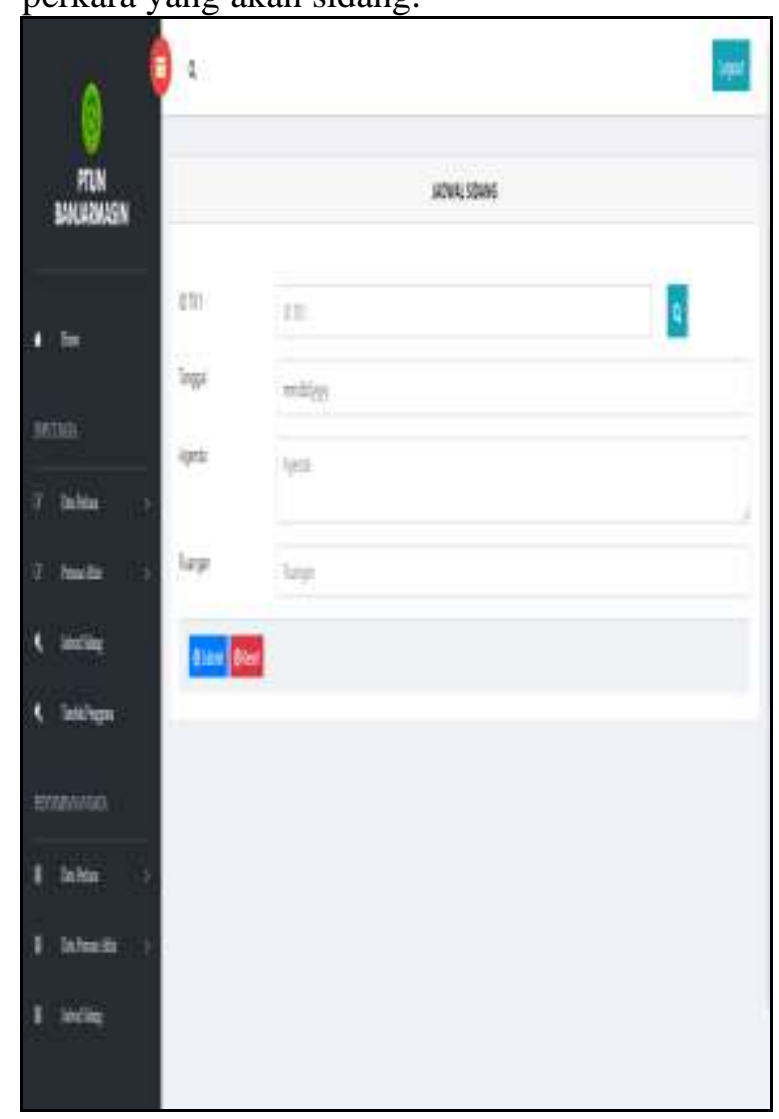

Gambar 10. Tampilan Input Jadwal Sidang

\section{j. Laporan Perkara TK1}

Laporan Perkara TK1 merupakan output dari input Perkara TK1, laporan ini dicetak berdasarkan data perbulan.

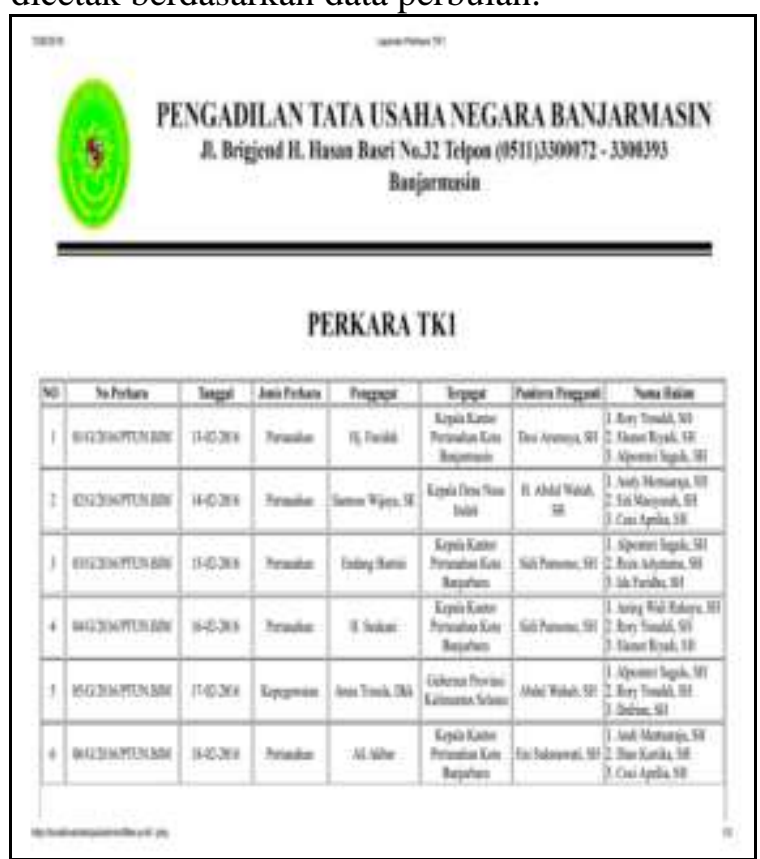

Gambar 11. Laporan Perkara TK1

\section{k. Laporan Perkara Banding}

Laporan Perkara Banding merupakan output dari input Perkara Banding, laporan ini dicetak berdasarkan data perbulan.

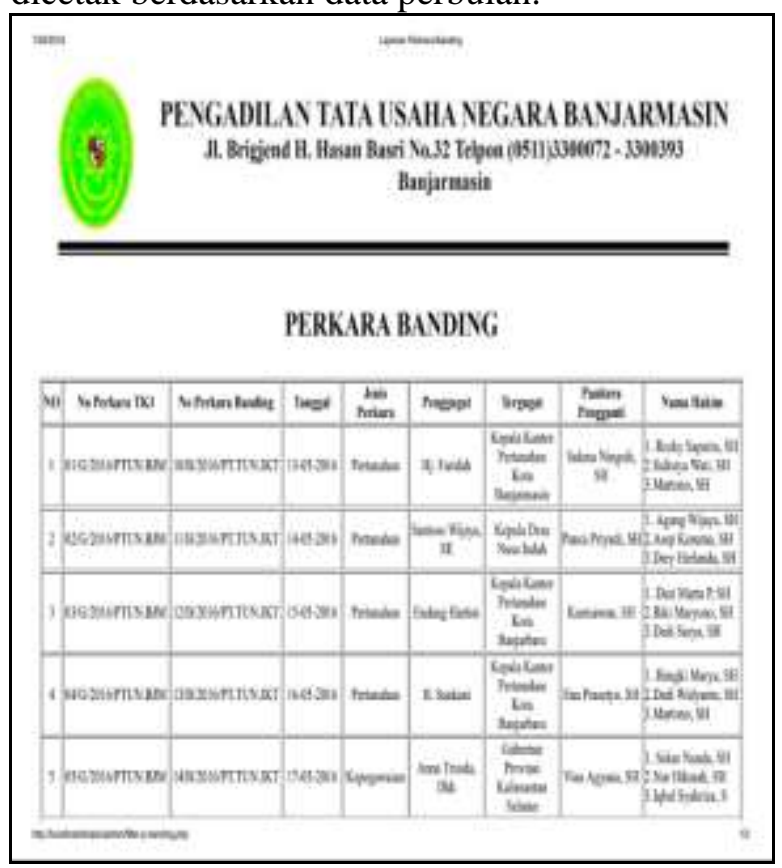

Gambar 12. Laporan Perkara Banding

\section{l. Laporan Perkara Kasasi}


Laporan Perkara Kasasi merupakan output dari input Perkara Kasasi, laporan ini dicetak berdasarkan data perbulan.

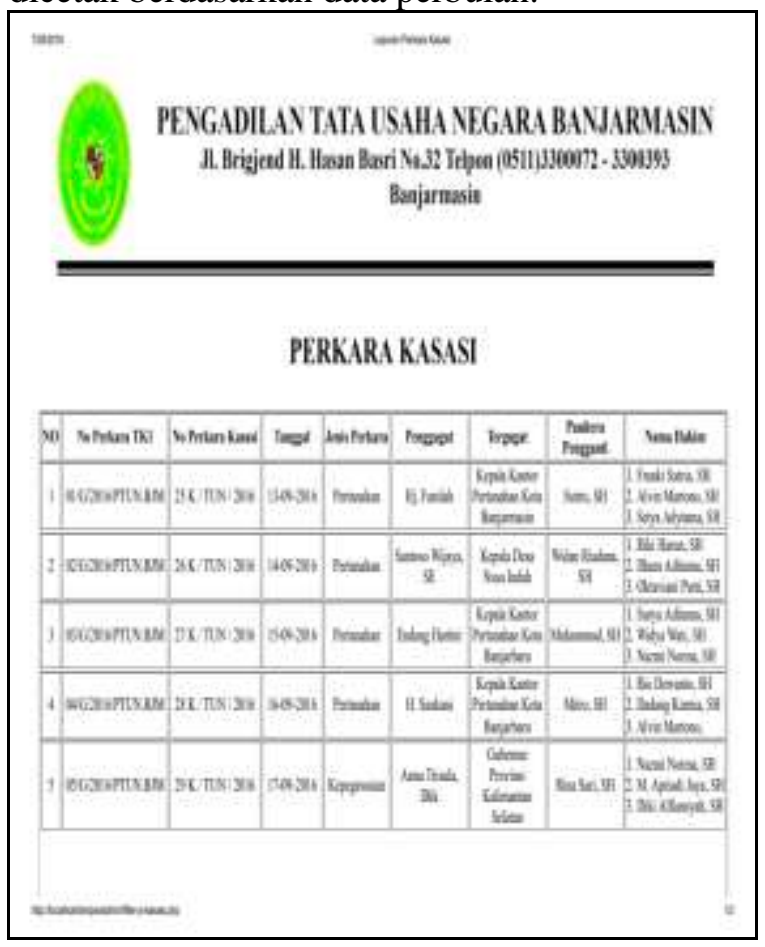

Gambar 13. Laporan Perkara Kasasi

\section{m. Perkara PK}

Laporan Perkara PK merupakan output dari input Perkara PK, laporan ini dicetak berdasarkan data perbulan.

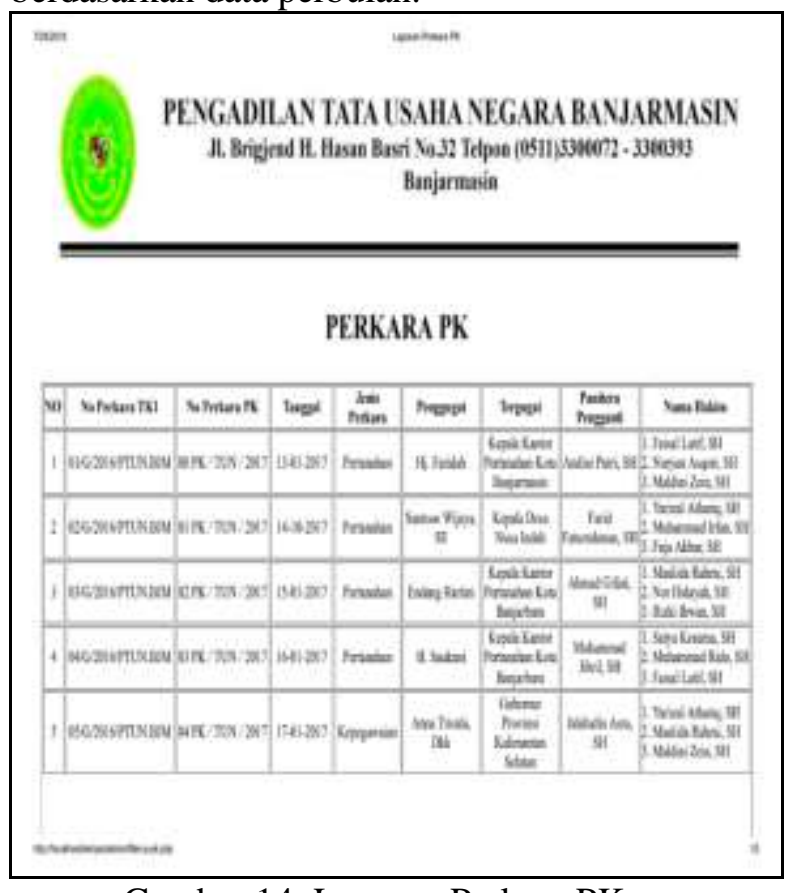

Gambar 14. Laporan Perkara PK

\section{n. Perkara Eksekusi}

Laporan Perkara Eksekusi merupakan output dari input Perkara Eksekusi, laporan ini dicetak berdasarkan data perbulan.

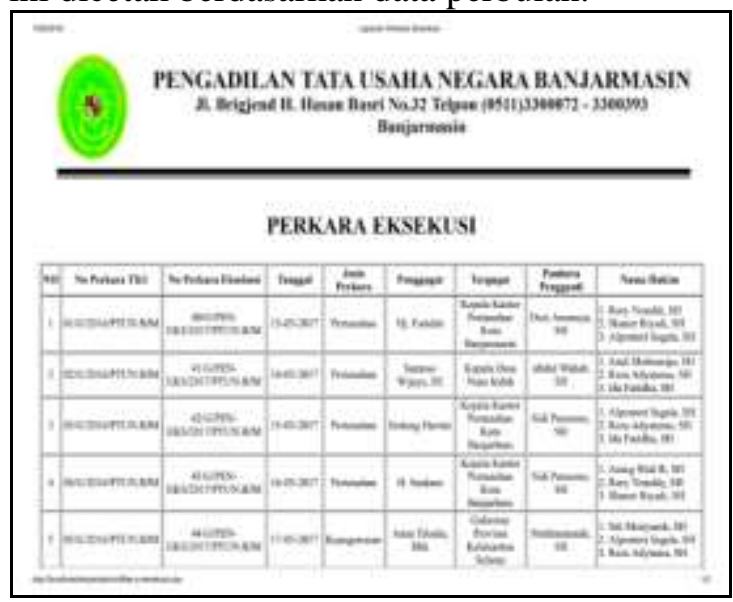

Gambar 15. Laporan Perkara Eksekusi

\section{o. Jadwal Sidang}

Laporan jadwal sidang merupakan output dari input jadwal sidang, laporan ini dicetak berdasarkan data perbulan.

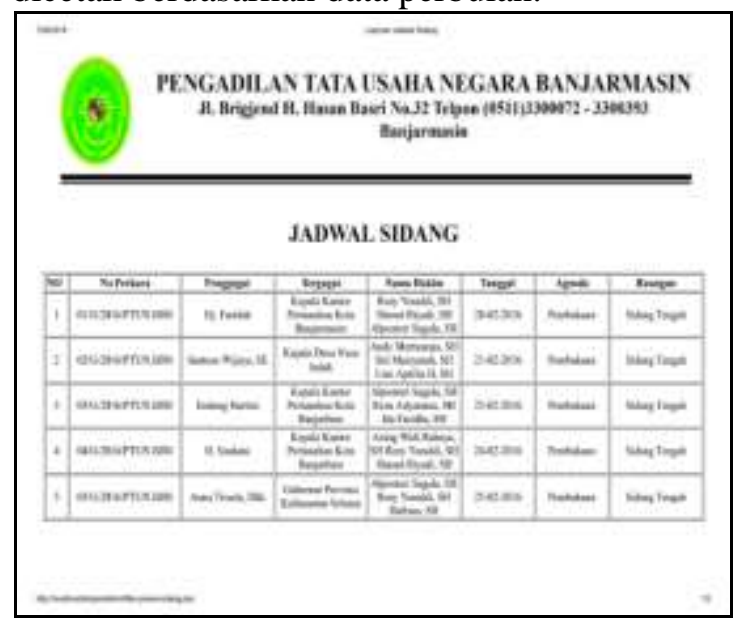

Gambar 16. Laporan Jadwal Sidang

\section{KESIMPULAN}

Berdasarkan dari analisa dan penelitian yang dilakukan dapat ditarik kesimpulan mengenai Implementasi Sistem Informasi Manajemen Data Perkara Pada Pengadilan Tata Usaha Negara Banjarmasin, adapun sebagai berikut :

1. Dengan adanya Sistem Informasi Manajemen Data Perkara ini bisa memudahkan dalam pengolahan data dan laporan dengan baik dan akurat.

2. Dengan adanya Sistem Informasi Manajemen Data Perkara ini semua data perkara, data banding dan data kasasi serta 
data eksekusi terintegrasi dengan baik sehingga data bisa tersaji dengan cepat, sesuai dengan yang diinginkan.

\section{REFERENSI}

Jogiyanto, \& Hartono. (2009). Analisis \& Desain Sistem Informasi. Yogyakart: Andi Ofset.

Raharjo, B. (2011). Belajar Pemrograman Web Dengan PHP + Oracle. Bandung: Informatika Bandung.
Peranginangin, \& Kasiman. (2006). Aplikasi WEB dengan PHP dan MySQL. Yogyakarta: ANDI

Indrajani. (2008). Konsep Dasar Data Dan Informasi. Retrieved from Metode Belajar:

Suyanto. (2016, April). Pengertian HTML Menurut Para Ahli Dan Pakar. 